\title{
Review
}

\section{Modern management of diabetic foot complications}

\author{
Cristian Bălălău ${ }^{1,2}$, Nicolae Bacalbașa ${ }^{1}$, Carolina Negrei ${ }^{1}$, Bianca Gălățeanu ${ }^{3}$, Octav \\ Ghinghină $^{1,4}$, Oana-Denisa Bălălău ${ }^{1}$, Ioana Păunică ${ }^{1}$, Marinela Chioveanu ${ }^{5}$ \\ ${ }^{1}$ Carol Davila University of Medicine and Pharmacy, Bucharest, Romania \\ ${ }^{2}$ St. Pantelimon Emergency Clinical Hospital, Department of Surgery, Bucharest, Romania \\ ${ }^{3}$ University of Bucharest, Department of Biochemistry and Molecular Biology, Bucharest, Romania \\ ${ }^{4}$ St. Ioan Emergency Clinical Hospital, Department of Surgery, Bucharest, Romania \\ ${ }^{5}$ Sanador Hospital, Bucharest, Romania
}

\begin{abstract}
Diabetes mellitus comprises a heterogeneous group of metabolic abnormalities, characterized by chronic hyperglycemia, resulting from a deficiency in insulin secretion, a deficiency in action, or from both situations. In its evolution, diabetes can lead to acute or chronic complications, which can be avoided or whose progression can be slowed by optimal glycemic control, provided by the effective treatment, diet, physical activity and glycemic monitoring.

One of the most common complications of diabetes is diabetic neuropathy which, in combination or not with peripheral arterial disease, may result in leg changes (ulcers, gangrene, amputations), changes that are known under the heading of diabetic foot.

The risk of developing leg ulcer is $25 \%$ in the life of a patient with type 1 or 2 diabetes, and amputations of varying degrees may sometimes be necessary. These can, however, be prevented by active screening characterized by the neurological examination for neuropathic signs, and the vascular examination to highlight the presence of peripheral arterial disease.

Therefore, in order to prevent the appearance of leg ulcers and to reduce the morbidity associated with it, it is important to diagnose and manage risk factors.

\section{Keywords \\ Highlights}

: diabetic foot, complications, ulcer, risk factors, modern management, amputation

$\checkmark$ An appropriate screening and classification of the foot wound in diabetic patients, plus a targeted education (therapeutic shoes, etc.) are essential to reducing lower-extremity amputation risk.

$\checkmark$ Infection and peripheral artery disease are essential factors increasing the amputation risk, and must be addressed appropriately when the symptomatology become acute (mechanical, enzymatic, autolytic, and surgical debridement).
\end{abstract}

To cite this article: Bălălău C, Bacalbașa N, Negrei C, Gălățeanu B, Ghinghină O, Bălălău OD, Păunică I, Chioveanu M. Modern management of diabetic foot complications. J Clin Invest Surg. 2019; 4(1): 5-9. DOI: $10.25083 / 2559.5555 / 4.1 / 5.9$ 


\section{Introduction}

Diabetic foot lesions are responsible for most hospitalizations in patients with diabetes (1). In the US, diabetes is the main cause of non-traumatic amputations in the lower limbs, with a $5 \%$ incidence of ulcers each year, out of which $1 \%$ require amputation $(2,3)$. In a study on 1,300 patients with type 2 diabetes, the incidence of amputations was 3.8/ 1,000 patients/ year, and the amputation predictors were ulceration, ankle brachial index $<0.9$, increased glycosylated hemoglobin and the presence of neuropathy (4).

Diabetic neuropathy is an important risk factor for the occurrence of leg ulcers by reducing their sensitivity, and patients with neuropathic ulcers have the highest risk of premature cardiovascular death. The association of autonomic diabetic neuropathy with the decrease or absence of sweating in the legs can lead to dehydration and cracked skin that can become germ-entry gates, thus favoring the further development of the infection $(5,6)$.

\section{Discussions}

Foot infections are one of the most common problems in patients with diabetes due to microcirculatory damage, local trauma, absence of lower limb sensations due to neuropathy, and can be of varying degrees, from simple infection to cellulitis or osteomyelitis (7). Generally, leg infections in patients with diabetes are more severe and difficult to treat due to microcirculatory damage, heal more difficultly compared to infections in patients without diabetes, have a higher mortality rate in those with chronic osteomyelitis and those with acute necrotic soft tissues infections $(8,9)$.

The most common and important risk factors for developing diabetic foot are $(3,4)$ :

- older leg ulcers;

- diabetic neuropathy with loss of protective sensitivity;

- deformations of the legs;

- vascular disease of the lower limbs.

Also, minor but equally important risk factors are (3, 4):

- shoe trauma;

- skin and nail mycoses;

- limiting joint mobility;

- degree of patient's activity.

Diabetic foot evaluation

According to current guidelines, the clinical examination of the foot should be performed at the time of diagnosis in type 2 diabetes and 5 years after diagnosis in type 1 diabetes. Subsequently, the examination should be performed annually for both types of diabetes or more frequently for patients with risk factors $(1,10)$.

The components of the clinical examination are as follows:

The anamnesis that should focus on the patient's personal history, the presence of neuropathy symptoms, peripheral ischemia and the detection of other diabetic complications such as kidney disease or diabetic retinopathy $(1,2)$.

The clinical examination consists in the examination of the skin (ulcers, signs of infection, color, humidity), musculoskeletal inspection (deformities, Charcot foot), neurological examination and vascular examination $(1,3)$.

Diagnostic neuropathic screening tests include testing protective sensitivity with a 10-gram monofilament, which is the preferred method for assessing the risk of leg ulcers, testing vibration sensitivity with the $128 \mathrm{~Hz}$ diapason, testing thermal and pain sensitivity $(1,3,10)$.

The initial vascular examination involves the inspection and palpation of the arterial pulse, which can reveal the decrease or absence of the pulse in the lower limbs, decrease of the skin temperature, thin skin or atrophic skin. After that, patients with clinical signs of peripheral arterial disease can undergo more thorough investigations, such as the ankle brachial index or Doppler examination of the lower limbs $(1,11)$.

Ankle brachial index (Table 1) is the ratio between the systolic pressure of the calf artery and the brachial systolic pressure, and it is interpreted as follows $(3,11)$ :

Table 1. Ankle brachial index

\begin{tabular}{|c|c|}
\hline $\begin{array}{c}\text { ANKLE } \\
\text { BRACHIAL } \\
\text { INDEX }\end{array}$ & \multicolumn{1}{|c|}{ SIGNIFICATION } \\
\hline $0.9-1.3$ & normal \\
\hline$>1.3$ & $\begin{array}{l}\text { calcified vessels or mediocalcosis } \\
\text { requires further investigations }\end{array}$ \\
\hline$<0.9$ & $\begin{array}{l}\text { occlusive arterial disease } \\
\text { arterial obstruction and } \\
\text { claudication }\end{array}$ \\
\hline$<0.4-0.9$ & $\begin{array}{l}\text { multi-layered arterial disease } \\
\text { resting pain } \\
\text { tissular necrosis }\end{array}$ \\
\hline
\end{tabular}


Classification of ulceration risk (3):

Group 0: without neuropathy;

Group 1: the presence of neuropathy, but without foot deformities or peripheral vascular disease;

Group 2: the presence of neuropathy, deformities and the presence of peripheral vascular disease;

Group 3: history of leg ulcers or amputations of lower extremities.

The treatment consists of an interdisciplinary collaboration involving both diabetes physicians and family doctors, surgeons, neurologists, orthopedists, psychologists and strategies for the prevention of ulcers and their treatment. Ulcer prevention can be achieved by optimizing glycemic control, treating dyslipidemia and high blood pressure, education on foot care and other methods (1).

In a study comparing conventional and intensive glycemic control in diabetic patients with leg ulcers, no benefit nor negative effect of intensive treatment compared to conventional treatment on foot ulcers in diabetic patients was found (12). Regarding the antidiabetic therapy, the increase in the risk of amputation in type 2 diabetic patients treated with SGLT-2 inhibitors has been demonstrated compared to other treatments for type 2 diabetes (13).

A randomized clinical trial attempted to evaluate the potential benefit of various drugs on the diabetic foot and demonstrated a possible benefit of statins in the healing process of the diabetic foot ulcer (14).

The ulcer treatment is based on its complexity, the presence or absence of ischemia, the presence or absence of infection and its severity. Thus, the methods may range from surgical or chemical debridement, pressure relief, treatment of infections to tissue repair stimulation $(1,15$, 16).

The management of ulcers requires wound care, the use of appropriate shoes, debridement whenever indicated, antibiotic therapy when infection is present, optimal glycemic control, and the assessment of peripheral arterial insufficiency $(15,16)$. Debridement represents the removal of necrotic tissue by means of surgery or other methods, the surgical method being preferred because it seems to be more effective, especially in the presence of infection (1).

Regarding the effects of debridement on the evolution of the diabetic foot injury, a meta-analysis was done, which revealed the effectiveness of certain methods of debridement, such as surgical, autolytic and larval methods, but it did not show the superiority of any method due to methodological limitations (17).

The presence of infection often requires oral antibiotic treatment in patients with mild and moderate infections, and hospitalization and parenteral antibiotic treatment for severe life-threatening infections (1).

In a study conducted in China in 2016, where the efficacy of Ertapenem vs. Piperacillin/ Tazobactam was compared in diabetic foot infections, the treatment with Ertapenem was shown to be non-inferior to Piperacillin/ Tazobactam in Chinese patients with diabetes and foot infections (18).

Because foot infections are associated with increased mortality and morbidity, the risk factors for diabetic foot infections, such as neuropathy, peripheral arterial disease and glycemic control, should be identified and immediate treatment should be instituted to manage the wound (debridement, cleaning and pressure release), antibiotic therapy, glycemic control and electrolyte balance control. Last, but not least, the evaluation should be made to allow revascularization by angioplasty or bypass (19).

Patients with a high risk of diabetic foot, those with diabetic neuropathy, leg deformities or previous amputations are recommended for therapeutic footwear. In patients in whom ulcers are not reduced by more than $50 \%$ after 4 weeks of conventional treatment, adjuvant therapy is recommended, and revascularization should be considered in those associated with peripheral arterial disease (20).

The amputation will be performed if the infection does not disappear and if it threatens the patient's life, when the pain caused by peripheral ischemia is very severe and vascular reconstruction cannot be performed, or if the quality of life is clearly affected by the presence of ulcer compared to a minor amputation $(1,21)$.

The amputation level is determined by the surgeon, and it is performed according to several criteria, out of which an important role is the severity and the degree of ischemia. Restricted amputations that preserve as much as possible from the foot are desirable and are characterized by amputations of fingers and trans metatarsal amputations, keeping the heel as far as possible (1).

Trans metatarsal amputation is a common intervention and it seems to be the most effective way to keep the limb viable, and its goal is to remove dead tissue, to promote healing, and to maintain a functional limb, and also improve the patient's quality of life. This is indicated in the case of chronic forefoot ulceration, forefoot gangrene, their combination and severe crushed forefoot (22).

A randomized controlled trial involving 17 studies and 1,655 participants revealed the effectiveness of skin graft use and tissue replacement in combination with standard therapy in patients with diabetic ulcers, demonstrating a 
higher rate of ulcer healing and a lower rate amputation versus standard therapy alone (23).

\section{Conclusions}

Considering the morbidity and mortality associated with foot lesions in the diabetic patient, an active screening and an interdisciplinary management based on the collaboration between the diabetes surgeon, orthopedist, vascular surgeon, neurologist and family physician is required to prevent their occurrence, for their efficient treatment when they exist and for increasing the quality of life in the patient with diabetes.

\section{Conflict of interest disclosure}

There are no known conflicts of interest in the publication of this article. The manuscript was read and approved by all authors.

\section{Compliance with ethical standards}

Any aspect of the work covered in this manuscript has been conducted with the ethical approval of all relevant bodies and that such approvals are acknowledged within the manuscript.

\section{References}

1. Zubair M, Ahmad J. Role of growth factors and cytokines in diabetic foot ulcer healing: A detailed review. Rev Endocr Metab Disord. 2019 Apr 1. DOI: 10.1007/s11154-019-09492-1.

2. Xia N, Morteza A, Yang F, Cao H, Wang A. Review of the role of cigarette smoking in diabetic foot. $J$ Diabetes Investig. 2019; 10(2): 202-215. PMID: 30300476, DOI: 10.1111/jdi.12952.

3. Boulton AJ. Pressure and the diabetic foot: clinical science and offloading techniques. Am J Surg. 2004 May. 187 (5A): 17S- 24S. PMID: 15147987, DOI: 10.1016/S0002-9610(03)00297-6

4. Beuker BJ, van Deursen RW, Price P, Manning EA, van Baal JG, Harding KG. Plantar pressure in offloading devices used in diabetic ulcer treatement. Wound Repair Regen. 2005; 13(6): 537-42. PMID: 16283868, DOI: 10.1111/j.1524-475X.2005.00075.x

5. Brocco E, Ninkovic S, Marin M, Whisstock C, Bruseghin M, Boschetti G, Viti R, Forlini W, Volpe A. Diabetic foot management: multidisciplinary approach for advanced lesion rescue. J Cardiovasc Surg (Torino). 2018; 59(5): 670-84. PMID: 29808982, DOI: 10.23736/S0021-9509.18.10606-9
6. Rice JB, Desai U, Cummings AK, Birnbaum HG, Skornicki M, Parsons NB. Burden of diabetic foot ulcers for Medicare and private insurers. Diabetes Care. 2014; 37(3): 651-8. PMID: 24186882, DOI: $10.2337 / \mathrm{dc} 13-2176$

7. Chammas NK, Hill RL, Edmonds ME. Increased Mortality in Diabetic Foot Ulcer Patients: The Significance of Ulcer Type. J Diabetes Res. 2016; 2016: 2879809. DOI: 10.1155/2016/2879809

8. Matos M, Mendes R, Silva AB, Sousa N. Physical activity and exercise on diabetic foot related outcomes: A systematic review. Diabetes Res Clin Pract. 2018; 139: 81-90. PMID: 29477503, DOI: 10.1016/j.diabres.2018.02.020

9. Qi M, Zhou Q, Zeng W, Wu L, Zhao S, Chen W, Luo C, Shen M, Zhang J, Tang CE. Growth factors in the pathogenesis of diabetic foot ulcers. Front Biosci (Landmark Ed). 2018; 23: 310-317. PMID: 28930549

10. Gregg EW, Sorlie P, Paulose-Ram R, Gu Q, Eberhardt MS, Wolz M, Burt V, Curtin L, Engelgau M, Geiss L. 1999-2000 national health and nutrition examination survey. Prevalence of lower- extremity disease in the US adult population $>=40$ years of age with and without diabetes: 1999-2000 national health and nutrition examination survey. Diabetes Care. 2004; 27(7): 1591-7. PMID: 15220233, DOI: 10.2337/diacare.27.7.1591

11. Ramsey SD, Newton K, Blouhg D, McCulloch DK, Sandhu N, Reiber GE, Wagner EH, Incidence, outcomes, and cost of foot ulcers in patients with diabetes. Diabetes Care. 1999; 22(3): 382-7. PMID: 10097914, DOI: 10.2337/diacare.22.3.382

12. Ashmore Z, Vickers B, La Fontaine J, Shibuya N, Jupiter DC. Patient Impressions of Possible Catastrophic Outcomes after Diabetic Foot Ulceration. Curr Diabetes Rev. 2018; 14(4): 376-388. PMID: 28606045 , DOI: $10.2174 / 1573399813666170612103814$

13. Adeghate J, Nurulain S, Tekes K, Fehér E, Kalász H, Adeghate E. Novel biological therapies for the treatment of diabetic foot ulcers. Expert Opin Biol Ther. 2017; 17(8): 979-87. PMID: 28532226, DOI: 10.1080/14712598.2017.1333596

14. Rusescu A, Zainea V, Iana OR, Ioniță I, BurceaDragomiroiu GTA, Ștefănescu DC, Badiu DC, Gherghiceanu F, Pietroşanu C, Pop CS, Hainarosie R, Hainarosie M. Management options in the sudden hearing loss of a diabetic patient. J Mind Med Sci. 2019; 6(1): 19-25. DOI: 10.22543/7674.61.P1925 
15. Singh N, Armstrong DG, Lipsky BA, Preventing foot ulcers in patients with diabetes. JAMA. 2005; 293(2): 217-28. PMID: 15644549, DOI: 10.1001/jama.293.2.217

16. Pantea-Stoian A, Ditu G, Diculescu M, Manuc M, Suceveanu I, Manuc D, Diaconu C, Suceveanu AP, Nitipir C, Hainarosie R, Poiana C, Serafinceanu C. Pancreatogenic type 3C diabetes. J Mind Med Sci. 2018; 5(2): 270-277. DOI: 10.22543/7674.52.P270277

17. Xu ZR, Ran XW, Xian Y, Yan XD, Yuan GY, Mu SM, Shen JF, Zhang BS, Gan WJ, Wang J. Ertapenem versus piperacilin / tazobactam for diabetic foot infections in China: a Phase 3, multicentre, randomized, double- blind, active- controlled, noninferiority trial. J Antimicrob Chemother. 2016; 71(6): 1688-96. PMID: 26888908, DOI: 10.1093/jac/dkw004

18. Fernando ME, Seneviratne RM, Tan YM, Lazzarini PA, Sangla KS, Cunningham M, Buttner PG, Golledge J. Intensive versus conventional glycaemic control for treating diabetic foot ulcers. Cochrane Database Syst Rev. 2016; (1): CD010764. PMID: 26758576, DOI: 10.1002/14651858.CD010764.pub2

19. Fox JD, Baquerizo- Nole KL, Macquhae F, Herskovitz I, Freedman JB, Vileikyte L, Margolis DJ, Kirsner RS, Statins may be associated with six- week diabetic foot ulcer healing. Wound Repair Regen. 2016; 24(2): 45457. PMID: 26748844, DOI: 10.1111/wrr.12400
20. Chang HY, Singh S, Mansour O, Baksh S, Alexander GC, Association Between Sodium- Glucose Cotransporter 2 Inhibitors and Lower Extremity Amputation Among Patients With Type 2 Diabetes. JAMA Intern Med. 2018; 178(9): 1190-1198. PMID: 30105373, DOI: 10.1001/jamainternmed.2018.3034

21. Elraiyah T, Domecq JP, Prutsky G, Tsapas A, Nabhan M, Frykberg RG, Hasan R, Firwana B, Prokop LJ, Murad MH. A systematic review and meta- analysis of debridement methods for chronic diabetic foot ulcers. $J$ Vasc Surg. 2016; 63(2 Suppl): 37S-45S.e1-2. PMID: 26804366, DOI: 10.1016/j.jvs.2015.10.002.

22. Santema TB, Poyck PP, Ubbink DT. Skin grafting and tissue replacement for treating foot ulcers in people with diabetes. Cochrane Database Syst Rev. 2016 Feb 11; 2:CD011255. PMID: 26866804, DOI: 10.1002/14651858.CD011255.pub2.

23. Hingorani A, LaMuraglia GM, Henke P, Meissner MH, Loretz L, Zinszer KM, Driver VR, Frykberg R, Carman TL, Marston W, Mills JL Sr, Murad MH. The management of diabetic foot: A clinical practice guideline by the Society for Vascular Surgery in colaboration with the American Podiatric Medical Association and the Society for Vascular Medicine. $J$ Vasc Surg. 2016; 63(2 Suppl): 3S-21S. PMID: 26804367, DOI: 10.1016/j.jvs.2015.10.003 